\title{
Türkmen Türkçesinde -(I)p / -(U)p Eki ve İşlevleri
}

\author{
Dr. Öğr. Üyesi Engin Gökçür \\ Gümüşhane Üniversitesi Edebiyat Fakültesi \\ Türk Dili ve Edebiyatı Bölümü \\ engingokcur@gumushane.edu.tr
}

Öz

-(I)p / -(U)p eki Türk dilinin tarihî gelişimi süresince çoğunlukla zarf-fiil eki olarak kullanılmıştır. Bu ekin getirildiği sözcükler cümlenin ana yargısını "durum, zaman, tarz gibi yönlerden niteler. Türkiye Türkçesinde çoğunlukla durum ve tarz bildiren "-ArAK" zarf-fiil eki Türkmen Türkçesinde kullanılmadığından bu zarf-fiil ekinin işlevini Türkmen Türkçesinde -(I)p / -(U)p eki üstlenmiştir. Bu ek günümüz Türkmen Türkçesinde yukarıda belirtilen işleviyle çoğu zaman durum ve tarz ifade eden zarf-fiiller teşkil eder. Bunun yanında getirildiği sözcüğü kendisinden sonraki yardımcı fiillere bağlayarak tasvir fiili de teşkil ettiği görülür. Türkiye Türkçesinde süreklilik ve çıkma ifade eden tasvir fiillerinin; Türkmen Türkçesinde ise yeterlilik, tezlik süreklilik, süreç, bitiş, çıkma ve başlama ifade eden tasvir fillerinin teşkilinde görev yaptı̆̆ı görülür. Bu ek bitmiş, tamamlanmış yargıları başka bir yargıya bağlama gibi bir işleve sahip olduğu için diğer çağdaş Türk lehçelerinde olduğu gibi Türkmen Türkçesinde de zamanla zarf-fiil eki işlevinin yanında, öğrenilen geçmiş zaman kipinin teşkilinde kullanılmıştır. Türkmen Türkçesinde özellikle teklik ve çokluk ikinci ve üçüncü şahısların öğrenilen geçmiş zaman teşkilinde bu ekin kullanıldığ görülür. Bu ek Türkmen Türkçesinde kendisinden sonra "-DIr" bildirme ekiyle birleşmek suretiyle öğrenilen geçmiş zaman teşkilinde kullanılır.

Anahtar Kelimeler: Türkmen Türkçesi, zarf-fiil, tasvir fiili, kip, öğrenilen geçmiş zaman. 


\title{
Suffixes -(I)p /-(U)p and Their Functions in Turkmen Turkish
}

\begin{abstract}
Suffixes -(I)p and -(U)p have been used as verbal adverb suffixes during the historical development of Turkish language. When these suffixes are added, verbs modify the central meaning in terms of 'situation, time and style.' Therefore, they are used instead of the verbal adverb suffix (- arak), not used in Turkmen Turkish, that is used to refer to situation and style. These suffixes mostly form verbal adverbs stating situation and style with their function mentioned above in Turkmen Turkish. Besides, when they are added to verbs, they form descriptive verbs by attaching verbs to auxiliary verbs. In this case, it has been seen that they take role in the formation of descriptive verbs that refer to sufficiency, quickness, duration, process, ending and starting. As these suffixes have the function of attaching completed conclusions to another conclusion, they have lost their verbal adverb function in time in Azerbaijani Turkish as in Turkmen Turkish and have been used as past perfect tense. These suffixes are used especially in second-person singular and plural in past perfect form in Turkmen Turkish. They are used in the form of past perfect tense when followed by the (dır) affix.
\end{abstract}

Keywords: Turkmen Turkish, verbal adverb, descriptive verbs, mode, past perfect tense. 


\section{GİRIŞ}

-(I)p, -(U)p eki Türk dilinin ilk yazılı belgelerinden itibaren çoğunlukla zarf-fiil eki olarak kullanılmıştır. Bu ek getirildiği fiille cümlenin asıl yargısını değişik yönlerden niteleyen zarflar üretir. Getirildiği sözcüklere durum, neden-sonuç, tarz gibi işlevler yükleyerek cümlenin asıl yargısını niteler.

Zarf-fiil eki işleviyle aynı zamanda kendisinden sonraki yardımcı fiillere bağlanarak tasvir fiillerinin teşkilinde de görev üstlenir. Yeterlik, tezlik, süreklilik, süreç, bitiş, çıkma ve başlama ifade eden tasvir fillerindeki yardımcı fiillerin yapılış tarzını ifade eder. Söz konusu ek diğer Türk lehçelerinde olduğu gibi Türkmen Türkçesinde de zamanla zarf-fiil eki işlevinin yanında öğrenilen geçmiş zaman kipinin teşkilinde kullanılır. Tespit ettiğimiz söz konusu işlevlerinden dolayı bu çalışmayı başlıca iki başlık altında incelemeyi uygun gördük:

1. Zarf-fiil Eki İşlevi

2. Kip Eki Teşkil Etme İşlevi

\section{1. -(I)P, -(U)P EKİNINN ZARF-FIïL İŞLEVI}

\subsubsection{Ekin Tarihî Türk Lehçelerindeki Kullanımı}

1.1.1.1. -(I)p, -(U)p eki Türk dilinin ilk yazılı eserlerinin verildiği Eski Türkçe döneminden günümüz çağdaş Türk lehçelerine uzanan süreçte çoğunlukla zarf-fiil eki işlevinde kullanılmıştır. Türk dilinin ilk yazılı belgeleri olan Köktürk ve Uygur dönemi eserlerinde "-p" ve genişletilmiş “-(I)pAn, -(U)pAn" şekillerinde kullanıldığı görülür. Zarffiil eki işleviyle Köktürk ve Uygur dönemi eserlerinde çoğunlukla cümlenin asıl yargısını değişik yönlerden nitelediği görülür:

Äşitip uḳar biz. "dinleyip anlarız”; yarlıġıñznı äşitip...ögüzüg aḳıtıp...uluşınta tuğtılar "emrinizi işitip... nehri akıtıp... memleketinde yeniden doğdular."; krmaputug sıp tsuy ḳıltımız ärsär "Karmapatha'yı kırıp, günah işledik ise..." (Gabain 2007:84).

sünüg batımı ḳarı̀ söküpän kögmän yışıg tog̉a yorıp, ḳıḳız bodunug uda basdım. "Mızrak batımı karı söküp Kögmen yaylağına doğru yürüyüp Kırgız milletini mahvettim."; yaylıg taġına ag̀ıpan yaylayur turur men. "Yazlık dağıma çıkıp yazı geçiriyorum." (Gabain 2007:84).

Süçig sabın yemşak agın arıp ırak bodunug anca yagutir ermiş. "Tatlı sözlerle ve yumuşak ipekli kumaşlarla kandırıp uzak halkları böylece yaklaştırırlar imiş."(Tekin 2010:20).

Süçig sabına yemşak agısına arturup üküş türük bodun öltüg. "Tatlı sözlerine ve yumuşak ipekli kumaşlarına kanıp (ey) Türk halk çok sayıda öldün!” (Tekin 2010:20).

Yemä bodısavat tegin bu uluş bodun ayıg kılınçlıg kılmışın körüp ärtinü busuşlug kadgulug bolup iglayu balıkka kirdi. "Yine Prens Bodisatva bu ülke insanlarının kötü işler yaptığını görüp çok fazla üzüntü ve kaygı duyarak ağlaya ağlaya şehre girdi." (Köken 2011:12)

bo savig eşidip üçünçi mahasatve tegin iki äçilerine ötrü inçä tep ötündi. "Bu sözü işitip üçüncü prens Mahasatva iki ağabeyine şöyle söyledi." (Gulcalı 2013:76).

1.1.1.2. Bu ek Orta Türkçe döneminde Kuzeydoğu ve Güneybatı grubu Türk lehçelerinde zarf-fiil eki işleviyle oldukça yaygın bir şekilde kullanılmıştır. Karahanlı, Harezm ve Kıpçak Türkçesi metinlerinde ekin “-p, -(I)p, -(U)p, -bAn, -(I)bAn, -(U)bAn, (U)pAn" şekillerinde zarf-fiil eki işleviyle kullanıldığı görülür: 
Boşug kör bu tapnur özin kul kılıp / muniñ emgekin yulġu tapġın bilip. “Hür adama bak, o kendisini kul edip hizmette bulunur. Bunun hizmetini ve çektiği sıkıntıyı bilip onu kurtarmak gerekir." (Arat 1991:309).

Itım tutup kodı çaldı / anıñ tüsin kıra yoldı. / başın alıp kodı saldı. / boguz alıp tükel bogdı. "O, kurdu alıp yere çaldı. / Onun tüylerini yoldu. / Başını alıp aşağı attı. /Boğazını kesip onu tamamen boğdu" (Ercilasun- Akkoyunlu 2014:240).

Tivelerni tutup burunduḳlap yolga kivürdiler. / Minip atḳa uş ol fîl tig oturdı. / andag cemâl körüben / ḳurını kurşaban / bu üç birikiben bolur bil îmân (Ata 2014:106).

ol frişte sövünüp karşı bardı. / Sançar keldi buğday enlü bolupan. (Karamanlığlu 1994:147-147).

1.1.1.3. Eski Anadolu ve Osmanlı Türkçesi döneminde ek “-(U)p, -(U)bAn, -(U)bAnI, (U)bAnIn" şekillerinde zarf-fiil eki işleviyle kullanılır:

sevinüp şâd olur görince anlar. / Yüzin görüp urur yire özin her dem gül-i hod-rû. / Varuban bunları kılduk ziyâret. / Cân u dil milkini hış görmeyibenin ḩışmile / ètdiler tâlân u vîrân gözlerüñle kaşlaruñ. (Gülsevin 1997:133).

Gözin açup kimseye bakmazıdı. / dügün idüp Varḳaya tîz viresiz. / ...dutubanı bizi burca așalar. / dönübenin geldiler üçi bile. (Köktekin 2008:126).

it gibi uv uv idüp döndi hemân. / Cem idüben ol hevazın leşkerin. (Şahin 2003:70).

baglanuban, gerïben, olubanı gelesiz, diyübeni (Timurtaş 1999:445).

1.1.1.4. Çağatay Türkçesinde bu zarf-fiil eki "-p, -(I)bAn, -(U)bAn, -bAn" şekillerinde kullanılır: yarutḳay dèben "parlatayım diyerek", alduruban "aldırı", körüben "görüp, görünce", kuçup "kucaklayıp", susap "susayıp", tilep "dileyip" (Argunşah 2013:156-157).

\subsubsection{Ekin Güneybatı Grubu Türk Lehçelerindeki Kullanımı}

Bu ek Güneybatı Grubu Türk lehçelerinden Türkiye Türkçesi ile Azerbaycan Türkçesinde de günümüzde cümlenin yargısını zaman, durum, tarz gibi yönlerden niteleyen zarflar teşkil eder. Söz konusu ek Türkiye Türkçesinde -(y)Ip, -(y)Up şekillerinde kullanılır (Korkmaz 2017:853). Azerbaycan Türkçesinde “-(I)b, -(U)b" şekillerinde kullanılan ek çoğunlukla fiilin yapılma tarzını ve zamanını belirten zarflar teşkil eder: Gördüm Kasım emi bir daş üstünde $\boldsymbol{e y l e s ̧ i b ~ d e j y i r . / ~ A r ı k ~ t r a k t o r c ̧ u ~ n e ~ i s e ~ d e y i n e - d e y i n e ~ d u ̈ s ̧ u ̈ ̈ b ~ m a s ̧ ı n ı n ~ a r h a s ı n a ~}$ keçdi. / Buz layları onun ayagları altında parçalanıb seslenirdi. / Bir dağ kęçisi başını galdırıb onu gördü ve var gücü ile tullanıb gaçdı. / O mücrünü getirib onun gabağında açdı. / Goca başını divara süykeyib gözlerini yumdu (Kazımov 2010:297).

\subsubsection{Ekin Türkmen Türkçesindeki Kullanımı}

Türkmen Türkçesi edebî eserleri üzerine yaptığımız incelemelerde -(I)p, -(U)p ekinin zarf-fiil işleviyle değişik anlamlar ifade edecek şekilde kullanıldığını tespit ettik:

1.1.3.1. -(I)p, -(U)p eki zarf-fiil işleviyle kullanıldığı durumlarda cümlenin asıl yargisı niteliğindeki fiili değişik yönlerden niteler. Bu ek Türkmen Türkçesinde getirildiği ikilemeli sözcüklerde asıl fiilin yapılma tarzını belirleyen zarflar türetir. Bu yönüyle Türkiye Türkçesindeki "....A ...A; -ArAk" zarf-fiil eklerinin işlevini üstlenir.

İişaan Aağa sığırımızı gaçıramızda men gıı̆ıııp-gıı̆ırıp sesimi gırdırıpdırın. "Molla Efendi, sığırımızı kaybettiğimizde ben bağıra bağıra sesimi yitirmişim." (Kerbabayev 1992:195).

Permaan her sözüni ooylanıp-ooylanıp gürlemääge başladı. "Perman her sözünü düşünerek konuşmaya başladı." (Govşudov 1989:758). 
Ol "Şu uğra gitsem çıkarın." diyip, başğa uğra süryäär, yöne yene aylanıp-aylanıp, öñki yerine gelyäär. "O 'Şu yöne gitsem çıarım.' diye başka yöne sürüyor, yalnız yine dolana dolana önceki yerine geliyor." (Govşudov 1989:84).

Ussa omrulıp-omrulıp, elinde diñe bir tutam bolup galan ağaca geñirğenip seretdi. "Usta ufala ufala elinde yalnızca bir parça kalan ağaca şaşırarak baktı." (Govşudov 1989:570).

1.1.3.2. Bu ek cümlede asıl yargı konumundaki fiili durum, tarz gibi yönlerden niteleyerek cümleye sebep-sonuç ilişkisi anlamı katar. Türkmen Türkçesinde -(I)p, -(U)p zarf-fiil ekini alan bu sözcükler Türkiye Türkçesinde eylemin yapılma tarzını ifade eden "diye" zarfiyla çevrilebilir:

Yeri nääme gülyääsiñ?-diyip soradı. " 'Peki, neden gülüyorsun?' diye sordu." (Kerbabayev 1992:9).

Yalak iişaan oları ööz üstüne Allaa taraplayın iiberilen belaa diyip düşündi. "Molla Yalak onların kendisine Allah tarfından gönderilmiş bir bela diye algıladı." (Kerbabayev 1992:219).

Ol "Şuu gün orup yetişsem, suv noobatım gelyäänçää, oran yoruncalarım guraap boğubermeli bede bolyaar diyip caan edip, ot yatıryaardı. " $\mathrm{O}$, 'Bugün biçip yetişsem su nöbetim gelinceye kadar biçtiğim yoncalar kuruyup bağlanacak yonca olur.' diye çabalayıp, ot yığıyordu." (Aşır 2012:2).

Çerkez ol aadamlarıñ galaadan çıkanına, cülğeden-cülğe eğni yükli yool sökenine aazından bäş-altı gün bolandır diyip ooyladı. "Çerkez 'O adamların kaleden çıkmaları, vadiden vadiye sırtlarında yükle yol almaları en az beş gün olmuştur.' diye düşündü." (Kerbabayev 1992:116).

1.1.3.3. Türkmen Türkçesinde bu ek çoğunlukla cümlenin asıl yargısının yapılma tarzını ifade eden zarflar teşkil eder. Bu durumda söz konusu eki alan fiilimsilerle cümlenin yükleminde belirtilen yargının eş zamanlı gerçekleşmesi söz konusudur (Clark 1998:353). Ek bu işleviyle Türkiye Türkçesinde kullanılan -(y)Ip / - (y)Up ve -ArAk zarf-fiil ekleriyle aynı görevdedir.

Övezmıraat baatır oña gözi düşenden, yerinden sıçraap turdı. “Övezmırat Batır'ın ona gözü iliştiğinde yerinden sıçrayarak kalktı." (Govşudov 1989:89)

Bir gadak halvaanı zaarın yalbarıp / Aydanından sähel arzaan alarsıñ. "Yarım kilo helvayı iniltiyle yalvarıp / Söylediğinden biraz daha ucuz alırsın." (Kara 1997:580).

Maşınıñ yelğini Mıradıñ yüzüne gözüne uranda ol mähnet tiğriñ aşaağına düşerli bolup alcıraanda gapdalından ılğaap gelenleriñ biiri onuñ goltuğından tutup alıp gaçdı. “Kamyonun rüzgârı Murat'ın yüzüne gözüne vurduğu vakit o kocaman tekerleğin altına düşecek olup kendini kaybettiği anda yanına koşturup gelenlerden biri onu koltuğundan tutarak uzaklaştı." (Kerbabayev 1992:30).

Soñra veziire garaap "Bar, siziñ aydanıñız bolsun." diyyäär. "Sonra vezire bakıp / bakarak 'Peki, sizin dediğiniz olsun.' diyor." (Kakalıyeva-Otuzov 1995:229).

Ortasında iki saanı stolı uzınlığına yaanaşdırıp goyup üstüni türli güller bilen bezääp, her hiili içğileri setirlääp goydular. "Ortasında iki masayı uzunlamasına yanaşı koyup, üzerini çeşitli çiçeklerle bezeyip, her çeşit içeceği dizip / dizerek bıraktılar." (Deryayev 1981:144).

Şonda daa görmedik bolan bolup sen / Süydi usuul bilen golçaa guyyaarsıñ. "O zaman da görmezlikten gelip / gelerek sütü yavaşça kovaya dökersin." (Kara 1997:576).

SEFAD, 2018 (39): 73-86 
Baranımdan soñ suuratımı aldırıp size-de iibererin. "Gittikten sonra fotoğrafımı çektirip size de gönderirim." (Kerbabayev 1992:45).

1.1.3.4. -(I)p / -(U)p zarf-fiil eki birbirinden bağımsız olarak gerçekleşen iki yargıyı birbirine bağlar. Bu nedenle bu eke bağlama zarf-fiili adı da verilir (Banguoğlu 2011:428-429; Bozkurt 1994:163-164). Bu ek bitmiş, gerçekleşmiş yan yargı konumundaki hareketi cümlenin asıl yargısına bağlama görevinde kullanıldığı için bazı kaynaklarda farklı bir gramer kategorisi içerisinde bağfiil olarak adlandırıldığı görülür (Bayraktar 2004: 139; Delice 2012). Ek, getirildiği sözcücükteki eylemin cümledeki asıl yargısından daha önce gerçekleştiğini belirtmek için kullanılır:

Hazandır akraap ööz gelmeli vağtı gelip, gezeğini geçirip gidipdi. "Eylül ve ekimin geleceği vakit gelmiş, sırasını geçirmiş, gitmişti." (Govşudov 1989:238).

Tecene barıp gaydıpdık - diyip, Permaan coğaap berdi. “Tecen'e gidip / gitmiş dönmüştük diye Perman cevap verdi." (Govşudov 1989:900).

Aaz yörä̈̈p köp yörääp üçünci dövüñ yaanına barıpdır. "Az yürümüş, çok yürümüş üçüncü devin yanına varmış.” (Kakalıyeva-Otuzov 1995:113).

Mıraat yöreyään yolunı, sovulcak köçesini yalnışıp, ikinci bir köçää düşdi. "Mırat yürüyeceği yolu, sapacağı sokağı şaşırıp ikinci bir sokağa girdi." (Kerbabayev 1992:30).

Öñürti onuñ öözüni çaağırıp, näähiili aadamdığını göreli, gürleşeliñ.. "Önce onun kendisini çağırıp nasıl bir insan olduğunu görelim, konuşalım..." (Kakalıyeva-Otuzov 1995:196).

1.1.3.5. -(I)p / -(U)p zarf-fiil ekini alan fiil kendisinden sonra eş ya da karşıt anlam ifade eden başka bir sözcükle birlikte kullanılarak sürekli ya da art arda tekrarlanan olayları/durumları karşılar:

Gumuñ eteğine yetip, şol cülgää düşüp, iki sesyetim yöreseñ, aylanıp-dolanıp, şol guyınıñ meydaanına çıkyaarsıñ. "Çölün kenarına ulaşıp şu vadiye inip, sesin ulaşacağı yer kadar yürüsen döne dolaşa bu kumluk alana ulaşırsın." (Govşudov 1989:242).

Zıbagül yalbarı-yakarıp, onı zoordan goydurdı. "Zibagül yalvara yakara onu zorla oturttu." (Govşudov 1989:616).

Emmaa bu indeğsiz gelyään mıhmaanlar Gülsoltaanı haalıs gisıp-govurdı. "Lakin bu habersiz gelen misafirler Gölsoltan'ı çok sıkıştırdı." (Govşudov 1989:644).

Capbaklar yaalı tirkeşip, gerişden- gerşe, gayadan-gayaa inip-çıkıp, ep-esli yool yörediler. "Capbaklar gibi ardı ardına dizilip dağdan dağa, kayadan kayaya, ine çıka hayli yol yürüdüler." (Govşudov 1989:830).

Iyip-içip otursak, keyp çeksek, oñatca dınç alsak..." diydi. "Yiyip içip otursak, keyif çeksek rahatça dinlensek..." dedi. (Atayev 2015: 108).

-Orazsoltaan, beýdip yanıp-köyüp, öözüñi horlaap yörme, mert bol. "-Orazsoltan böyle yana yakıla kendini üzme, metin ol." (Deryayev 1960:109).

1.1.3.6. -(I)p / -(U)p zarf-fiil ekini alan fiil kendisinden sonra olumsuzluk ekini alan şekliyle tekrarlı kullanıldığı takdirde getirildiği sözcükle cümlenin asıl yargısı arasındaki zaman aralığının çok kısa olduğunu ya da eş değerde olduğunu ifade eder:

-Yaapdan geçip-geçmäänkääm Nummat aağa dağı göründi-dää. "Ben kanaldan geçmemişken Nummat Ağabey dahi göründü." (Atayev 2015: 164).

Sapar bir ayağını äätlääp, sümüp-sümmäänkää, Nurmäämmet Sapar'ın iki kebzesiniñ aarasyndan aak saplını dikdi. "Sapar bir ayağını atıp geçmeden Nurmäämmet Sapar'ın iki kaburgasının arasından ak saplıyı yerleştirdi." (Deryayev 1960:226). 
Men daagıñ eteğine çıkıp-çıkmaankaam oları̃ meni yañadandan ele salmakları mümkiin. " Ben dağın eteklerine çıkmadan onların beni yeniden yakalamaları mümkün(dür). (Kerbabayev 1992:120).

Şundan soñ bir hepde geçip-geçmäänkää iil aarasına bir hiili düşnüksiz mış-mışlar yayraap başladı. "Bundan sonra bir hafta geçmeden halk arasında belli belirsiz dedikodular yayılmaya başladı." (Govşudov 1989:370).

1.1.3.7. Bu ek "ne" soru zamiriyle oluşturulmuş yardımcı fiille kullanıldığında yine soru zarfı görevinde "nasıl, ne şekilde" anlamlarında kullanılır:

Yeri gizlar, gurgun mısiñz? Siz buu yerlere näädip düşdüñiz? "Peki, kızlar siz sağlıklı mısınız? Siz bu yerlere nasıl düştünüz?" (Kakalıyeva-Otuzov 1995:122).

-Onsoñ men näädip baayın atını goyup giderin? "Sonra ben bayın atını nasıl bırakıp giderim?" Govşudov 1989: 94).

1.1.3.8. -(I)p / -(U)p zarf-fiil eki zaman adlariyla oluşturulmuş fiillere getirilerek zaman belirten zarflar teşkil eder:

Şonuñ üçiin hem bir doysa üç-döört günlä̈̈p aacıkmaan gımıldamaan yatyaan eken. "Bunun için de bir doysa üç dört gün geçirip acıkmadan, kımıldamadan yatıyor imiş." (Kerbabayev 1992:255).

Permaan köp vağtlaap uuklaap bilmedi. "Ferman uzun süre uyuyamadı." (Govşudov 1989:816).

İki-üç günlääp Mıralıdan derek bolmaandır. “İki üç gün boyunca, Mıralı'dan haber çıkmamış." (Kerbabayev 1992:325).

Altı aaylaap gözledi, emmaa tapıp bilmedi. "Altı ay aradı ama bulamadı." (Govşudov 1989:394).

Üç günden soñ giiçlääp ol bir yerden geldi. "Üç günden sonra geç bir vakitte bir yerlerden geldi." (Govşudov 1989:358).

1.1.3.9. -(I)p / -(U)p eki dil adıyla oluşturulmuş fiillere gelerek onlardan tarz ve durum yönüyle cümlenin asıl yargısını niteleyen zarflar teşkil eder:

Avanes türkmençelääp, "Bolköynek bayar bilen tanşıñız, onuñ ayaalı bilenem tanşıñ" diyip, saayavaanlı ayaalı görkezdi. "Avanes Türkmence olarak 'Bolköynek Efendi ile tanışınız, onun eşiyle de ile tanışın!' diye elinde şemsiye olan kadını gösterdi." (Deryayev 1937: 145).

Polkovnik Bekmıraat baayı̃ eğnine kakıp, rusçalaap: "Yene iki günden Amanmıraadıñ gelnini gutlaap bilersiniz" diyip güldi. "Albay Bekmırat Bey'in omuzuna vurarak Rusça 'Yine iki güne kadar Annamırat'ın gelinini kutlayabilirsiniz.' deyip güldü." (Deryayev 1937: 150)

Avanes uyezd naçalniğiniñ ayaalına rusçalaap "Muña Bekmıraat bay diyyääler... “Avanes ilçe komutanının eşine Rusça ‘Buna Bekmırat Bay diyorlar.”... (Deryayev 1937: 172)

1.1.3.10. -(I)p / -(U)p zarf-fiil ekinin diğer bir görevi de tasvir fiillerinin teşkilinde kullanılmasıdır. -(I)p, -(U)p zarf-fiil eklerini alan fiil kendilerinden sonra başka bir fiile bağlanarak, süreklilik, tezlik, yeterlilik, başlangıç, bitiş ifade eden tasvir fiilleri teşkilinde kullanılır. Bu gruptaki fiillerde ikinci fiiller daha sonradan anlam kayması neticesinde kendi anlamını yitirir, kendinden önceki fiilin anlamını belirginleştiren bir yardımcı fiil işlevine bürünür. Tasvir fiilindeki -(I)p / -(U)p zarf-fiil eki esas fiil ile tasvir konumundaki yardımcı fiili tarz ifadesiyle birbirine bağlar. -(I)p / -(U)p zarf-fiil eki Türkmen Türkçesinde bu bağlamda "bil- ve bol-" yardımcı fiilleri ile yeterlik ifade eden tasvir fiillerinin; "ber-" yardımc fiiliyle tezlik ifade eden tasvir fiillerinin; "bar-, gel-, dur-, otur-, otır-, yör-, gal- ve 
yat-“ yardımcı fiilleri ile süreklilik, süreç ve yön” ifade eden tasvir fiilerinin; "çık-, gal-, geç-, goy-, goyber- ve git-“ yardımc fiilleri ile bitme / bitiş ifade eden tasvir fiillerinin; "başla- ve uğra-" yardımcı fiilleri ile başlangıç ifade eden tasvir fiillerinin teşkilinde bir görev üstlendiği görülür. -(I)p / -(U)p ekinin söz konusu işlevi için bazı kaynaklarda "Bağlandığ1 fiile süreklilik ve yineleme gibi kip anlamları yükleyen bir öncül ek olduğu, işlevsel ek tasnifi kategorisinde ise "bütünleşik ek" olarak adlandırılması gerektiği belirtilir (Delice 2009:711; 2012: 6).

Sen näähiili bu yerlere gelip bildin? "Sen bu yerlere nasıl gelebildin?" (KakalıyevaOtuzov 1995:123).

Men saña kööke edip bereyin. "Ben sana bisküvi yapıvereyim." (Kakalıyeva-Otuzov 1995:21).

Onuñ niiredediğini, nääme üçiindiğini aydıp durmă̆ın, elbetde gereği yook... "Onun nerede olduğunu, ne için olduğunu söyleyip durma, elbette gereği yok..." (Kerbabayev 1992:126).

Baatırıñ kaakası Annamıraat gürrüñ başlanalı bääri sesini çıkarmaan dımıp otıırdı. "Batır'ın babası Annamırat sohbet başladığından beri sesini çıkarmadan sessizce oturuyordu." (Kerbabayev 1992:71).

Bir gün oylanıp oturşına Yanrasatlık oğlı Garasatlıkdan soraan. "Bir gün düşünüp durururken Yanrasatlık oğlu Garasatlık'a sormuş." (Çarıyev 2004:37).

Bir gün ecesi öyde uuklaap yatırkaa oğlan ecesiniñ saçından yedi gat caayıñ açarını alıp, tamları açmaağa başlaapdır. "Bir gün annesi evde yatarken oğlan annesinin saçından yedi katlı evin anahtarını alıp, kapıları açmaya başlamış." (Kakalıyeva-Otuzov 1995:40).

Akıp baryaan suvı duruzıp. "Akıp giden suyu durdurup" (Kara 1997:164).

Ol tirseğine gıışarıp yatışına derrev uukaa gidipdir. "O dirseğine dayanıp yatarken derhal uykuya dalmış." (Kakalıyeva-Otuzov 1995:355).

Ol sool elindeki bir dövüm çörekden sağ eli bilen dövüm alıp, çörek iyip yörääp gelyäärdi. "O sol elindeki bir dilim ekmekten sağ eliyle bir parça alıp ekmek yiyerek yürüyordu." (Govşudov 1989: 13).

Yağam, döönüğem men yağıdırın, döönükdirin diyip aydıp gelenook. "Düşman da dönek de ben düşmanım ya da döneğim diye söylemiyor." (Govşudov 1989:164)

Gaydıp geldim ılğaap yören yooluña. "Dönüp geldim koşturduğun yola." (Kara 1997:236).

Päälvaanlar nahar iyip bolyaançaalar, garañkı gatılaşdı. "Pehlivanlar yemek yiyinceye kadar hava karardı." (Aşır 2012:27)

Gutarınçaañ oturmadık / Partalarıñ aă̆laap gaaldı. "Bitirinceye kadar oturmadığın / Sıraların ağlayakaldı." (Kara 1997:622).

$\mathrm{Ol}$ yiğit sorara zaat goymaan, hemme vakaanı gisğacık aydıp çıkdı "O yiğit bir şey sormaya hacet bırakmaksızın bütün vakayı kısaca anlattı" (Govşudov 1989:5).

Guraklık bilen geçen yaazıñ tomsı hem gurı epğek bilen tozaap geçdi. "Kuraklıkla geçen baharın yazı da kuru sıcakla savrulup gitti." (Govşudov 1989:731).

Ol beceren uyanını çaadırıñ bir duuluna gaharlı oklaap goyberdi. "O diktiği yem torbasını çadırın bir köşesine öfkeyle fırlatıverdi." (Govşudov 1989:63).

Soñ nayza sancıp, daş gapısında dikip goydı. "Sonra kılıcı batırıp dış kapısında asıverdi" (Govşudov 1989:187).

Armaan, turup gidere de çakım yook. "Yazık, kalkıp gitmeye de niyetim yok." (Kara 1997: 480). 
Şol barmana garaca öy aala şakırdı bilen ăgdarılıp gitdi. “O giderken karaca ev büyük bir gürültüyle devrildi.” (Kerbabayev 1992:229).

Meni hayraan gaaldıran / Sırı açıp başladı. "Beni şaşırtan sırrı açmaya başladı." (Kara 1997:314).

Övezmırat baatır atını sürüp uğradı. "Yiğit Övezmırat atını sürmeye başladı." (Govşudov 1989:388)

\section{2. -(I)P, -(U)P EKİNIN KİP EKİ İŞLEVI}

\subsection{Ekin Tarihî Türk Lehçelerinde Kullanımı}

-(I)p, -(U)p eki Türk dilinin tarihî dönemlerinde özellikle Harezm Türkçesinden itibaren 1. ve 2. tekil ve çoğul şahıslarda şahıs zamiri, 3. şahısta ise "-DIr, -DUr" ekiyle birleşmek suretiyle öğrenilen geçmiş zaman teşkilinde kullanılmıştır. Ekin Eski Türkçe ve Karahanlı Türkçesi metinlerinde kip eki olarak kullanımına rastlanmamıştır. Ekin "öğrenilen geçmiş zaman" işleviyle kullanımına Harezm Türkçesi metinlerinden itibaren rastlanır. Harezm Türkçesi metinlerinden birkaç tanesinde ek 1. ve 2. tekil ve çoğul şahıslarda şahıs zamiri, 3. şahısta ise "-DIr, -DUr" ekiyle birleşmek suretiyle öğrenilen geçmiş zaman teşkilinde kullanıldığı görülür: ant içipmen, işitip men, kelip men, fikr kılıp sen, yahşı kılıpdur, uyuklapdur, körüp miz, kelipsiz (Ata 2014:89).

Ek, şahıs ekleriyle ve "-DIr, -DUr" bildirme ekiyle "öğrenilen geçmiş zaman" işleviyle sonraki dönemlerde Güneybatı Türk lehçelerinden Eski Anadolu ve Osmanlı Türkçesinde, Güneydoğu Türk lehçelerinden Çağatay Türkçesinde ve Kuzeybatı Türk lehçelerinden Kıpçak Türkçesinde kullanılmaya devam etmiştir:

Keliptirmen, küyüpturuptirmin, keliptirbiz, biliptirsen, deptirsen, içiptirsen, almayıpsen, ayta bilipsen, keliptirsiz, keliptir, turuptur, boluptur, keliptirler (Karamanlığlu 1994:124).

Bolupmen "olmuşum", bilüptürmèn "bilmişim", kèlipmèn "gelmişim", ḳılıpturmèn "kılmışım", açıpsen "açmışsın", bolupsen "olmuşsun", sançıpdursen "saplamışsın", tolupturur "dolmuş", körüptürbiz "görmüşüz", kılıptursiz "kılmışsınız", biliptururlar "bilmişler" (Argunşah 2013:160).

İdüpven, arupsin, olupdurur, bulupdur, gelüpdür, gelmeyüpdür (Timurtaş 2005:140).

Ek söz konusu işleviyle bugün Güneybatı Türk lehçelerinden Azerbaycan Türkçesinde, Güneydoğu Türk lehçelerinden Özbek ve Uygur Türkçelerinde, Kuzeybatı Türk lehçelerinden Kırgız ve Kazak Türkçelerinde kullanılmaya devam etmektedir (Ata 2014:89).

\subsection{Ekin Güneybatı Grubu Türk Lehçelerinde Kullanımı}

“-(I)p, -(U)p” eki günümüzde Güney-batı Türk lehçelerinden Azerbaycan Türkçesinde ve Türkiye Türkçesinin doğu grubu ağızlarında hâlâ canlı bir şekilde öğrenilen geçmiş zaman eki olarak kullanılagelmektedir: Azerbaycan Türkçesinde "nekli keçmiş zaman" adı altında teklik ve çokluk 2. ve 3. şahıslarda bu şekil kullanılır:

Nėçe il yüzbaşılık $\dot{e} d i b$, ahırda bir nefer onun üstüne şer $\boldsymbol{a t \imath b} \mathrm{ki}$, guya Kasım yüzbaşı rüşvethordur. O sebebe möhrünü ve zencirini alıblar. / Bu eşgin tumundan kol da bitmeyib. / Yètimin elleri yara yètmeyib. / Şèyh Hèydär kocaya teref döndü: -Men atamı görmemişem, o da meni görmeyib (Kazımov 2010:231).

SEFAD, 2018 (39): 73-86 
Bu ek Türkiye Türkçesinin doğu grubu ağılarından Erzurum, Kars, Iğdır, Van ve Bitlis ağızlarında “-(I)p, -(U)p, -(I)f, -(U)f”" şekillerinde kullanılmaktadır: gelipsiz, gelipsen, yı̆̆ılıf, namaz gılıf, millet dă̆ılıf giden nen sonra... (Zülfikar 1992:18-19).

\subsection{Ekin Türkmen Türkçesindeki Kullanımı}

2.3.1. Türkmen Türkçesinde -(I)p / -(U)p zarf fiil eki -dIr / -dUr bildirme eki ile birleşip kalıplaşarak -(I)pdIr, -(U)pdUr şekilleriyle öğrenilen geçmiş zaman çekimini teşkil eder. Bu kip tarihi olayları, bir kişinin tanık olmadığı bir olayı, nesnel gerçekleri, sonradan başkasından öğrenilen ya da farkına varılan gerçekleri belirtirken kullanılır (Clark 1998 : 244-245).

Asıl men bu zaatları yaadımdanam çıkarıpdırın. "Aslında ben bu şeyleri hatırımdan da çıkarmışım" (Govşudov 1989:58)

Gara baatır, men hödür-keremi-de unudıpdırın. "Kara yiğit ben izzet ve ikramı da unutmuşum" (Govşudov 1989:236).

Bir deñziñ gırasından gidip baryaarkaa bir öyün üstünden barıpdır. "Bir denizin kenarından giderken bir evin üstüne varır." (Kakalıyeva-Otuzov 1995:421).

Öözi bilen äkidipdir coğaabın. "Kendisiyle göndermiştir cevabını." (Gurbannepesov 1995: 4).

Acal tövereğne guranda duzak / Yatıpdır geplemään yatıpdır uzak. "Ecel etrafına tuzak kurduğunda / Uzun (süre) konuşmadan yatmış." (Gurbannepesov 1995:4).

Omurıpdır onı bomba bööleği. "Koparmıştır onu bomba parçası." (Kara 1997: 18).

Bolyaar, tää seniñ alğıñ̃ beryäänçää değdirmerin-diyipdir. " 'Olur, senin alacağını verinceye kadar dokundurtmam.' demiş." (Çarıyev 2004.42).

Elhepuus, köp yatıpdırıs-ov diyip as̆̆ırıp yerinden galdı. " Allah Allah, çok yatmışız yahu!', deyip aksırıp yerinden kalktı." (Kakalıyeva-Otuzov 1995:64).

Biiriimiz döört yaaşında biiriimiz üç yaaşında yetim galıpdınz. "Birimiz dört yaşında, birimiz üç yaşında yetim kalmışız." (Kakalıyeva-Otuzov 1995:140).

Olar gören zaatlarınıñ düyşüdüğine yaa huuşuduğına akıl yetirip bilmään, işdääden kesilipdirler. "Onlar gördükleri şeyin hayal mi ya da gerçek mi olduğuna akıl erdirmeksizin iştahtan kesilmişler. (Kakalıyeva-Otuzov 1995:139).

Haas beteri oobaanıñ baayları süythoorları, diindaarları-da garıpları̃ üstüne atlayın münüpdirler. "Daha kötüsü köyün zenginleri, tefecileri, dindarları da fakirlerin sırtına ata biner gibi binmişler." (Kerbabayev 1992:164).

2.3.2. Türkmen Türkçesinde -(I)p / -(U)p eki Türk dilinin tarihî gelişimi süresince birbirinden bağımsız olarak gerçekleşen iki yargıyı birbirine bağlama işlevinin yanında Azerbaycan Türkçesinde teklik ve çokluk 2. ve 3. şahısların öğrenilen geçmiş zaman çekiminde kullanılmıştır (Kazımov 2010:297). Bu ek Türkmen Türkçesinde kendinden sonra teklik ve çokluk 2. şahıs ekleri üzerine gelir. Kip olarak da öğrenilen geçmiş zaman ifade eder.

Eyğilik mi inim giiçlääpsiñ gatı. "Hayırdır kardeşim geç vakitte yola çıkmışsın." (Kara 1997:742).

Maña akıl bererçe sen kim bolupsıñ? "Bana öğüt vermeye sen kim oluyorsun?" (Kerbabayev 1992:292).

Berekellaa, iiş bitiripsiñ - diydi. " 'Maşallah işi bitirmişsin.' dedi." (Govşudov 1989: 36).

Şol käärden başğa bir kääre geçipsiñiz. "Bu işten başka bir işe geçmişsiniz. (Govşudov 1989: 409).

SEFAD, 2018 (39): 73-86 
Hoş gelipsiñiz muhmaanlar diyip oları garşılaap hezzet-hormat eden. " ‘Hoş geldiniz misafirler.' diyerek onları karşılayıp izzet ve hürmet etmiş.” (Kakalıyeva-Otuzov 1995:268).

Perraaçlarıñ öyüni köydüripsiñiz aahırı. "Hizmetçilerin evini yakmışsınız sonunda" (Govşudov 1989:148).

2.3.3. Bu ek öğrenilen geçmiş zaman eki olarak birleşik zaman çekimlerinde kendisinden sonra hikaye birleşik zaman ekine getirilmektedir:

$\mathrm{Ol}$ şol aadamları çala sayğarandan bu iişde öözüni peydalı boların hasaap edipdi. "O, bu adamları az çok tanıdığından bu işte kendisini faydalı olurum (diye) hesaplamıştı." (Kerbabayev 1992:120).

Sebääbi atlılar eyyääm kovup yeterden aaraanı açıpdılar. "Çünkü atlılar çoktan ulaşılma mesafesini aşmıştılar." (Govşudov 1989:160).

Çerkez heniiz içeriik girmäänkää, öyüñ ışığından içerde üyşenip yerinden galıpdı da öyüñ günbatar duulunda öözüni ıkcamlaap durdı. "Çerkez henüz içeri girmeden evin ışığından içeride çekinip yerinden kalktı da evin batı köşesinde hazırlanmaya başladı" (Kerbabayev 1992:124).

Nazarı öyeren yılam öözi aaradan çıkıpdı. "Nazar'ı evlendirdiği yıl da kendisi vefat etmişti." (Aşır 2012:1)

Çerkez bir gün kaakasınıñ ızından baranda onuñ bilen bile ikinci bir bayırda ekilen buğdaylara aylanmaağa gidip, şol yerde güni giicikdiripdi. "Çerkez bir gün babasının ardından gittiğinde onunla ikinci bir bayırda ekilen buğdaylar arasında dolanmış, günü orada geçirmişti." (Kerbabayev 1992:110).

\section{SONUÇ}

-(I)p, -(U)p eki Türk dilinin tarihî dönemlerinde çoğunlukla zarf-fiil eki olarak kullanılmıştır. Bu ek getirildiği fiille cümlenin asıl yargısını değişik yönlerden niteleyen zarflar üretir. Ek getirildiği fiillere durum, neden-sonuç, tarz gibi işlevler yükleyerek cümlenin asıl yargısını niteler. Türkiye Türkçesinde fiilin yapılma tarzını belirten -ArAk zarf-fiil eki Türkmen Türkçesinde kullanılmamaktadır. Söz konusu ekin işlevini Türkmen Türkçesinde -(I)p, -(U)p eki üstlenmiştir. Bu nedenle bu ek söz konusu işleviyle oldukça geniş bir kullanım alanına sahiptir. Bu ek günümüze Türkmen Türkçesinde de yukarıda belirtilen işleviyle çoğu zaman durum ve tarz ifade eden zarf-fiiller teşkil eder. Bunun yanında getirildiği fiilleri kendisinden sonraki yardımcı fiillere bağlayarak tasvir fiili de teşkil ettiği görülür. Bu durumda yeterlilik, tezlik süreklilik, süreç, bitiş, çıkma ve başlama ifade eden tasvir fillerinin teşkilinde görev yaptığı görülür. Bu ek bitmiş tamamlanmış yargıları başka bir yargıya bağlama gibi bir işleve sahip olduğu için zamanla zarf-fiil eki olma işlevinin yanında öğrenilen geçmiş zaman kipinin teşkilinde de kullanılmıştır. Türkmen Türkçesinde özellikle teklik ve çokluk ikinci şahısların öğrenilen geçmiş zaman teşkilinde bu ekin kullanıldığı görülür. Bu ek Türkmen Türkçesinde kendisinden sonra “DIr" bildirme ekiyle birleşmek suretiyle öğrenilen geçmiş zaman teşkilinde kullanılır.

\section{SUMMARY}

Suffixes - (I) p and - (U) p have been used as verbal adverb suffixes during the historical development of Turkish language. These suffixes generate adverbs that modify the central meaning of the sentence from various aspects. Suffix modifies the central meaning of sentence by adding some functions such as situation, cause and effect and style. Verbal adverb suffix (- arak) that refers to situation and style in Turkish is not used in Turkmen 
Turkish. Suffixes - (I) p and - (U) p undertake the function of the mentioned suffix in Turkmen Turkish. These suffixes mostly form verbal adverbs stating situation and style with their function mentioned above in Turkmen Turkish. Since the first written sources of Turkish until today, suffixes - (I) p and - (U) p have been used to take the role in the formation of descriptive verbs that refer to sufficiency, quickness, duration, process, ending and starting. These suffixes have been mostly used in Turkish within the formation of descriptive verbs that refer to duration and reduplication compound verbs; dolanip dur-, didinip dur-, tekrarlayıp dur-, akıp git-, dalıp git-, geçip git-, uzayıp git-, dolup taş-, düşüp kalk-, kasıp kavur-, silip süpür-, uçup git- etc. This adverb in Turkmen Turkish takes role in formation of descriptive verbs; sufficiency with auxiliaries bil- and bol- , quickness with auxiliaries ber- , duration and process with auxiliaries bar-, gel-, git-, dur-, otur-, otır-, yör-, gal- and yat-, ending with auxiliaries çık-, gal-, geç-, goy-, goyber-, git and starting with auxiliaries başla-, uğra-.

As the suffixes have a function of attaching completed conclusions to another conclusion, they have lost their verbal adverb function in time in Azerbaijani Turkish as in Turkmen Turkish and used as past perfect tense. Suffixes - (I) p and - (U) p have been used as personal pronoun in first and second person singular and plural during the historical development of Turkish language especially since Khorezmian Turkic language and also as past perfect tense with auxiliaries "-DIr, -Dur" in third person. The suffixes have been used as modals in old Turkish and Karahan Turkish. In some texts of Khorezmian Turkic language these suffixes have been used as personal pronoun in first and second person singular and plural and as past perfect tense with auxiliaries "-DIr, -Dur" in third person as ant içipmen, işitip men, kelip men, fikr kılıp sen, yahşı kılıpdur, uyukllapdur, körüp miz, kelipsiz.

The suffixes have been used with the function of past perfect tense with auxiliaries "DIr, -Dur" and personal pronouns in old Anatolian Turkish and Ottoman Turkish from southwestern Turkish dialects, in Chagatai Turkish from south-eastern dialects and Kipchak Turkish from northwest dialects. These suffixes with their mentioned function are used nowadays in Azerbaijan Turkish from southwestern dialects, in Uzbek language and Uighur Turkish from south-eastern dialects and in Kyrgyz and Kazakh Turkish from northwest Turkish dialects. These suffixes are used with the function of past perfect tense with auxiliary "-DIr" in Turkmen Turkish. 


\section{KAYNAKÇA}

Arat, Reşit Rahmeti (1991). Kutadgu Bilig I Metin. Ankara: Türk Dil Kurumu Yay. 3. bs.

Argunşah, Mustafa (2013). Çağatay Türkçesi. İstanbul: Kesit Yay.

Aşır, Çarı (1986). Göreş. Aşgabat: Türkmenistan Neşriyatı.

Ata, Aysu (2014). Harezm-Altınordu Türkçesi. Ankara: Ankara Üniversitesi Yay.

Atayev, Kakamırat (2015). Ölüp-Direlen. Aşğabat.

Borcakov, A. - Sarıhanov, M. vd. (2000). Türkmen Diliniñ Grammatikası (Morfologiya), Aşğabat:

Türkmenistanıñ Prezidentiniñ Yanındakı Ilım ve Tehnika Baradakı Yokarı Geñeş Mağtımğulı Adındakı Dil ve Edebiyat İnstitutı.

Buran, Ahmet - Alkaya, Ercan vd. (2014). Çă̆daş Türk Yazı Dilleri (Güneybatı / Ŏ̆uz Grubu). Ankara: Akçă̆ Yay.

Clark, Larry (1998). Turkmen Referrence Grammar. Viesbaden: Otto Harrassovitz.

Çarıyev, O. (2004). Türkmen Şorta Sözleri. Türkmenistanıñ Milli Medeniyyet “Miras” Merkezi, Aşgabat: Türkmenbaşı Adındakı Türkmenistan Milli Gol-yazmaları İnstıtutı.

Delice, Hacı İbrahim (2009). "Türkçenin Öncül Ekliliği ve Türkçede Öncül Ek Taşıyan Yapılar". Turkish Studies, Volume 4/3, Spring: 703-716.

Delice, Hacı İbrahim (2012). “-Ip Eki Türkçede Hangi Kategorileri Oluşturmaktadır?”. V. Uluslararası Dünya Dili Türkçe Sempozyumu. Aydın

Deny, John (2009). Türk Dil Bilgisi. çev. Ali Ulvi Elöve. İstanbul: Kabalcı Yay.

Deryayev, Hıdır (1983). Ikbal. Aşğabat.

Durdıyeva, Amangül (2006). Ependi. Aşğabat: Türkmenistanıñ Milli Medeniyet «Miras» Merkezı Türkmenbaşı Adındakı Türkmenistan Milli Golyazmalar İnstıtutı.

Eckman, Janos (2011). Harezm, Kıpçak ve Çă̆atay Türkçesi Üzerine Araştırmalar. haz. Osman Fikri Sertkaya. Ankara: Akçağ Yay.

Ercilasun, Ahmet Bican-Akkoyunlu, Ziyat (2014). Dîvan̂u Lugati't Türk, Giriş-Metin-ÇeviriNotlar-Dizin. Ankara: Türk Dil Kurumu Yay.

Ergin, Muharrem, (1972). Türk Dil Bilgisi. İstanbul: Bayrak Yay.

Esenmedova, Amangül (2010). Häzirki Zaman Türkmen Dili (Morfologiya). Aşğabat: Türkmenistanıñ Bilim Ministirliği Mağtımğulı Adındakı Dövlet Üniversiteti.

Gabain, A. Von (2007). Eski Türkçenin Grameri. çev. Mehmet Akalın. Ankara: Türk Dil Kurumu Yay.

Govşudov, Ata (1989). Perman, Aşgabat: Türkmenistan Neşiryatı.

Gulcalı, Zemire (2013). Eski Uygurca Altun Yaruk Sudur'dan "Aç Bars" Hikâyesi. Ankara: Türk Dil Kurumu Yay.

Gurbannepesov, Kerim (1995). Oylanma Bayrı, Aşğabat: Dragon-Art.

Gülsevin, Gürer (1997). Eski Anadolu Türkçesinde Ekler. Ankara: Türk Dil Kurumu Yay.

Hamilton, James Russel (2011). İyi ve Kötü Prens Öyküsü. çev. Vedat Köken. Ankara: Türk Dil Kurumu Yay.

Hanser, Oskar (2003) Türkmence El Kitabı. çev. Zühal Karg1 Ölmez. İstanbul: Türk Dilleri Araştırmaları Dizisi 17. Kitap Matbaası.

Hocageldiyev, Nargılıç (1991) Gökdepe Galası. Aşgabat: TSSR Ilımlar Akademıası.

http://hazynasozluk.com

https:/enedilim.com/sozluk/soz

https://vvv.tdk.gov.tr

SEFAD, 2018 (39): 73-86 
Kakalıyeva, N. (2008). Türkmen Halk Ertekileri. Aşğabat: Türmenistanıñ Prezidentiniñ Yanındakı Ilım ve Tehnika Baradakı Yokarı Geñeş Magtımgulı Adındakı Dil ve Edebiyat İnstitutı.

Kakalıyeva, N.- Otuzov, S. (2008). Türkmen Halk Ertekileri. Aşğabat: Türkmenistanıñ Prezidentiniñ Yanındakı Ilım ve Tehnika Baradakı Yokarı Geñeş Mağtımğulı Adındakı Dil ve Edebiyat İnstitutı.

Kara, Mehmet (1997). Ata Atacanov'un Şiirleri I-II. Ankara: Türk Dil Kurumu Yay.

Kara, Mehmet (2012). Türkmen Türkçesi Grameri. İstanbul: Etkileşim Yay.

Karaağaç, Günay (2012). Türkçenin Dil Bilgisi. Ankara: Akçağ Yay.

Karadoğan, Ahmet (2004). "-Ip ile Kurulan Zarf-Fiili Parçalarının Türkmen Türkçesinden Türkiye Türkçesine Aktarımı Üzerine". Bilig (31): 207-218

Karamanlığlu, Ali Fehmi (1994). Kıpçak Türkçesi Grameri. Ankara: Türk Dil Kurumu Yay.

Kazımov, K.Ş. (2010). Müasir Azerbaycan Dili, Morfologiya. Bakı.

Kerbabayev, Berdi (1992). Saylanan Eserler (Hèkayalar, Povestler ve Folklor) Aşğabat: Mağarıf.

Korkmaz, Zeynep (2017). Türkiye Türkçesi Grameri, Şekil Bilgisi. Ankara: Türk Dil Kurumu Yay. 5. bs.

Köktekin, Kâzım (2011). Eski Anadolu Türkçesi. Erzurum: Fenomen Yay.

Şahin, Hatice (2003). Eski Anadolu Türkçesi. Ankara: Akçağ Yay.

Tekin, Talat (2010). Orhon Yazıtları. Ankara: Türk Dil Kurumu Yay. 4. bs.

Timurtaş, Faruk Kadri (2005). Eski Türkiye Türkçesi, XV. Yüzyll Gramer-Metin-Sözlük. Ankara: Akçă̆ Yay. 3. bs.

Türk Dil Kurumu (2009). Türkçe Sözlük. Ankara: Türk Dil Kurumu Yay.

Zülfikar, Hamza (1992). "Doğu Anadolu Ağızlarında Zaman Kavramı Taşıyan -1p / -1 Eki". Türkoloji Dergisi X (1): 113-115. 